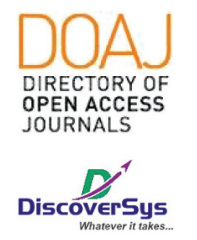

Published by DiscoverSys

\section{Gambaran sindrom metabolik pada pasien gangguan jiwa yang dirawat di rumah sakit jiwa provinsi Bali}

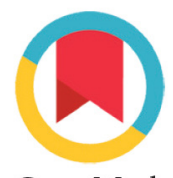

CrossMark

\author{
I Putu Arya Giri Prebawa ${ }^{1 *}$, Putu Kristalina Witari ${ }^{1}$, I Wayan Yuna Ariawan ${ }^{2}$
}

\section{ABSTRACT}

Introduction: Metabolic syndrome (MS) is a constellation of various disorders that can increase the risk of heart disease. MS is known to increase morbidity and mortality rates in psychiatric patients. However, MS in the population of mental disorders, especially in Bali, is still not well known. Methods:Across-sectionalanalyticdescriptivestudywas conducted in psychiatric patients treated at Bali Provincial Mental Hospital from January 2018 to February 2018. Inclusion criteria included inpatients who diagnosed with mental disorders based on DSM-IV criteria and those who had MS based on the National Cholesterol Education Program Adult Treatment Panel (NCE ATP III) criteria. Results: A total of 245 samples were included in this study with the prevalence of MS was $48.6 \%$. According on sex, female had higher proportion among MS patients than male $(42.8 \%$ vs
$60.7 \%$ ). In addition, the age group $>65$ years had the highest frequency $(75 \%)$ suffered from MS followed by age group of $45-65$ years $(54,9 \%)$. Based on the class of antipsychotic administered, MS patients with typical antipsychotic drug classes had the highest frequency, followed by the atypical group and combination of atypical and typical $(49.4 \%, 49.3 \%$, and $46.2 \%$, respectively). Among MS patients, most of them had obesity (87.3\%), followed by dyslipidemia, hypertension and impaired fasting glucose $(76.4 \%, 65.5 \%$, and $60.4 \%$, respectively). Conclusion: There is a high prevalence of metabolic syndrome among patients with mental disorder admitted to the Mental Hospital of Bali Province. Comprehensive multidisciplinary cooperation is required in the treating those with metabolic syndrome as comorbid.

Keywords: Metabolic Syndrome, Mental Disorders, Comorbid, Anti-psychotic

Cite This Article: Prebawa, I.P.A.G., Witari, P.K., Ariawan, I.W.Y. 2019. Gambaran sindrom metabolik pada pasien gangguan jiwa yang dirawat di rumah sakit jiwa provinsi Bali. Intisari Sains Medis 10 (2): 459-464. D0I: 10.1556/ism.v10i2.456

'Dokter Umum Rumah Sakit Jiwa Provinsi Bali, Bangli, Bali, Indonesia

${ }^{2}$ Dokter Spesialis Penyakit Dalam Rumah Sakit Jiwa Provinsi Bali, Bangli, Bali, Indonesia
*Korespondinsi :

I Putu Arya Giri Prebawa; Dokter Umum Rumah Sakit Jiwa Provinsi Bali, Bangli, Bali, Indonesia putu.aryagiri@gmail.com

Diterima : 21-03-2019

Disetujui : 17-07-2019

Diterbitkan : 18-07-2019

\title{
ABSTRAK
}

Pendahuluan: Sindrom metabolik (SM) merupakan kumpulan gejala yang dapat meningkatkan risiko terjadinya penyakit jantung. SM meningkatkan angka morbiditas dan mortalitas pasien gangguan jiwa. Angka SM pada populasi gangguan jiwa di Bali belum diketahui.

Metode: Penelitian ini adalah studi deskriptif analitik potong lintang pada pasien yang dirawat di RSJ Provinsi Bali periode Januari sampai Februari 2018. Kriteria inklusi pada penelitian ini adalah pasien rawat inap yang didiagnosis gangguan jiwa berdasarkan kriteria DSM-IV dan penderita SM berdasarkan kriteria National Cholesterol Education Program Adult Treatment Panel (NCEP ATP III). Hasil: Penelitian ini menggunakan 245 sampel. Prevalensi SM didapatkan sebesar $48,6 \%$. Berdasarkan jenis kelamin, perempuan lebih banyak menderita SM dibandingkan laki-laki ( $42,8 \%$ vs
$60,7 \%$ ). Kelompok umur $>65$ tahun memiliki persentase tertinggi (75\%) menderita SM diikuti oleh kelompok umur 45-65 tahun $(54,9 \%)$. Berdasarkan golongan antipsikotik yang didapatkan, penderita SM dengan golongan obat antipsikotik tipikal memiliki frekuensi tertinggi, selanjutnya golongan antipsikotik atipikal dan kombinasi atipikal dan tipikal $(49,4 \%, 49,3 \%, 46,2 \%)$. Obesitas menempati urutan paling banyak pada pasien yang mengalami SM( 87,3\%) dan selanjutnya diikuti oleh Dislipidemia , Hipertensi dan GDPT $(76,4 \%, 65,5 \%, 60,4 \%)$.

Kesimpulan: Terdapat prevalensi sindrom metabolik yang tinggi pada pasien gangguan jiwa yang dirawat di RSJ Provinsi Bali. Kerjasama multidisiplin ilmu secara komprehensif diperlukan dalam penanganan pasien gangguan jiwa dengan komorbid sindrom metabolik 


\section{PENDAHULUAN}

Sindrom Metabolik (SM) adalah kumpulan faktor resiko yang terjadi akibat adanya disregulasi metabolik yang berkaitan langsung dengan penyakit kardiovaskular. Selain pada populasi umum, SM juga dapat ditemukan pada populasi dengan gangguan jiwa.

Gangguan jiwa merupakan masalah yang terjadi diseluruh belahan dunia. Data statistik World Health Organization (WHO) mencatat terdapat sekitar 450 juta orang yang mengalami gangguan jiwa dan Indonesia memiliki populasi orang dengan gangguan jiwa (ODGJ) cukup tinggi. RISKESDAS 2013 mencatat 6\% penduduk Indonesia mengalami gangguan depresi dan kecemasan, dan sekitar 0,17 $\%$ penduduk mengalami gangguan jiwa berat. Provinsi Bali sendiri mencatat ada 9.000 orang dengan masalah gangguan jiwa. Bali masuk dalam lima besar provinsi dengan jumlah ODGJ terbanyak di Indonesia. ${ }^{1}$

Beberapa penelitian menunjukkan adanya kelainan metabolik pada pasien gangguan jiwa berat khususnya skizofrenia. Hal ini disebabkan karena adanya berbagai faktor yang saling berinteraksi satu sama lain. Beberapa literatur menunjukkan bahwa faktor genetik, pola hidup, kebiasaan pasien, kondisi klinis dan efek samping obat antipsikotik menjadi faktor yang paling berperan dalam timbulnya SM.,3

Terdapat berbagai kriteria yang digunakan untuk menentukan SM. Kriteria yang paling banyak diadopsi adalah kriteria yang dikeluarkan oleh The National Cholesterol Education Program Adult Treatment Panel III (NCEP ATP III) dengn komponen inti dari SM adalah obesitas, resistensi insulin, dislipidemia, dan hipertensi. ${ }^{3,4}$ Sindrom Metabolik yang muncul pada populasi umum maupun pada orang dengan gangguan jiwa meningkatkan resiko terjadinya morbiditas dan mortalitas yang berkaitan dengan penyakit kardiovaskular. Penyakit kardiovaskular bertanggung jawab untuk 30\% dari semua kematian. Penyakit ini juga merupakan penyebab kematian alami yang paling umum pada skizofrenia. Terhitung sebanyak $34 \%$ kematian pada pasien lakilaki dan 31\% kematian pada pasien wanita adalah akibat penyakit kardiovaskular. $^{5}$

Kejadian SM juga bervariasi sesuai dengan jenis kelamin, usia, etnis, perilaku, dan durasi penyakit gangguan jiwa. SM juga relatif tinggi pada ODGJ di negara-negara berkembang. Sebuah penelitian di Palestina menyebutkan angka SM pada ODGJ sebanyak $43,6 \%$, dengan $55,9 \%$ pada wanita dan $39 \%$ pada pasien laki-laki, sementara penelitian lain menunjukkan $38,7 \%$ pada pasien gangguan mental di Iran dan $43,6 \%$ di India. Selanjutnya, penelitian di negara-negara Asia Tenggara mencatat terdapat
46,7\% SM pada ODGJ di Malaysia, sekitar 46\% di Singapura, dan $37 \%$ di Thailand, yang semuanya lebih tinggi dibandingkan populasi umum pada negara-negara tersebut. ${ }^{6,7}$

Penelitian berkaitan dengan SM beserta komponennya pada pasien dengan gangguan jiwa di Indonesia dan Bali khususnya sejauh ini belum ditemukan oleh penulis. Oleh karena itu, sangat penting dilakukan penelitian untuk mendeteksi kejadian SM pada orang dengan gangguan jiwa.

\section{METODE}

\section{Subjek Penelitian}

Data dikumpulkan pada periode Januari hingga Februari 2018 dari 9 bangsal perawatan di Rumah Sakit Jiwa Provinsi Bali. Penelitian ini melibatkan 245 sampel dengan kriteria inklusi adalah pasien rawat inap yang telah didiagnosis dengan gangguan jiwa berdasarkan kriteria DSM-IV.

\section{Pengumpulan Data}

Informasi sosiodemografi dan klinis diperoleh melalui wawancara terstruktur dan selanjutnya diverifikasi dengan rekam medis pasien. Riwayat medis seperti hasil laboratorium, diagnosis dan obat-obatan yang digunakan didapat melalui penelusuran rekam medis. Semua pengukuran lingkar pinggang dilakukan langsung oleh peneliti. Pemeriksaan tekanan darah istirahat dilakukan dua kali pengukuran dengan interval 5 menit dan diambil menggunakan sphygmomanometer raksa dalam posisi duduk.

\section{Analisis Statistik}

Analisa data dilakukan dengan menggunakan perangkat lunak komputer dan software SPSS Windows versi 16.0. Cleaning data dilakukan terhadap semua variabel untuk mengetahui data yang tidak sesuai (missing). Uji statistik deskriptif dilakukan untuk menggambarkan karakteristik penderita dan distribusi frekuensi berbagai variabel. Analisis univariate terhadap variabel kelompok umur, jenis kelamin, golongan antpsikotik, diagnosis komorbid, dan diagnosis psikiatri. Tabulasi silang antara variabel status SM dengan variabel jenis kelamin, kelompok umur, golongan obat antipsikotik, hipertensi, obesitas, dislipidemia, gula darah puasa terganggu

\section{HASIL}

\section{Karakteristik Sosiodemografi Sampel}

Sampel dalam penelitian ini berjumlah 245 orang penderita gangguan jiwa yang menerima antipsikotik. Tabel dibawah menunjukkan karakteristik sosiodemografi sampel yang diteliti dalam penelitian ini. 
Tabel 1. Karakteristik Sosiodemografi Sampel ( $N=245)$

\begin{tabular}{|c|c|c|c|}
\hline & Variabel & Jumlah & Persentase \\
\hline \multirow{2}{*}{ Jenis Kelamin } & Laki-Laki & 166 & $67,8 \%$ \\
\hline & Perempuan & 79 & $32,2 \%$ \\
\hline \multirow[t]{4}{*}{ Kelompok Umur } & $12-25$ & 15 & $6,1 \%$ \\
\hline & $26-45$ & 120 & $49,0 \%$ \\
\hline & $45-65$ & 102 & $41,6 \%$ \\
\hline & $>65$ & 8 & $3,3 \%$ \\
\hline \multirow[t]{10}{*}{ Diagnosis Psikiatri } & Skizofrenia Hebefrenik & 152 & $62,0 \%$ \\
\hline & Demensia & 1 & $0,4 \%$ \\
\hline & Skizofrenia Paranoid & 30 & $12,2 \%$ \\
\hline & Skizofrenia Simplek & 9 & $3,7 \%$ \\
\hline & Skizofrenia YTT & 8 & $3,3 \%$ \\
\hline & Skizoafektif & 12 & $4,9 \%$ \\
\hline & $\begin{array}{l}\text { Gangguan Psikotik Lir Skizofrenia } \\
\text { Akut }\end{array}$ & 12 & $4,9 \%$ \\
\hline & Retardasi Mental & 8 & $3,3 \%$ \\
\hline & Gangguan Mental Organik & 10 & $4,1 \%$ \\
\hline & Episode Depresi Berat & 3 & $1,2 \%$ \\
\hline \multirow{3}{*}{$\begin{array}{l}\text { Diagnosis } \\
\text { Ko,Morbid }\end{array}$} & Hiperuricemia & 13 & $5,3 \%$ \\
\hline & Gagal ginjal kronis & 1 & $0,4 \%$ \\
\hline & Epilepsi & 9 & $3,7 \%$ \\
\hline \multirow{3}{*}{$\begin{array}{l}\text { Gol, Obat } \\
\text { Antipsikotik }\end{array}$} & TA & 95 & $38,8 \%$ \\
\hline & AA & 83 & $33,9 \%$ \\
\hline & $\mathrm{TA}+\mathrm{AA}$ & 67 & $27,3 \%$ \\
\hline
\end{tabular}

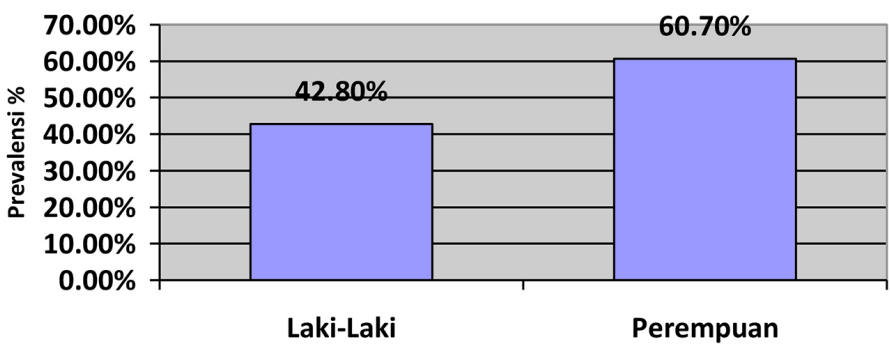

Grafik 1. Prevalensi Sindrom Metabolik Berdasarkan Jenis Kelamin

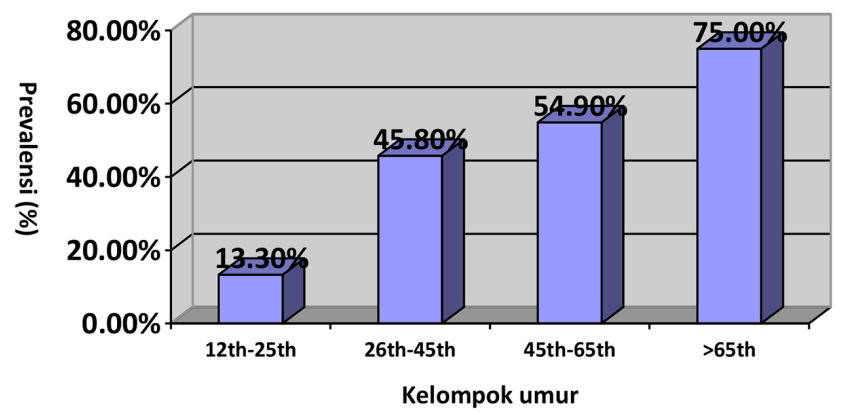

Grafik 2. Prevalensi Sindrom Metabolik Berdasarkan Kelompok Umur

\section{Prevalensi Sindrom Metabolik}

Pada penelitian ini, prevalensi SM pada laki-laki lebih sedikit dibandingkan perempuan. Ditemukan 71 sampel laki-laki yang memenuhi kriteria SM atau $42,8 \%$ dari keseluruhan sampel berjenis kelamin laki-laki dan 48 sampel (60,7\%) pada jenis kelamin perempuan.

Kelompok umur yang paling banyak mengalami sindrom metabolik adalah kelompok umur $>65$ tahun, dimana terdapat 6 sampel yang mengalami SM atau $75 \%$ dari semua sampel yang berumur $>65$ tahun. Kelompok umur $45^{\text {th }}-65^{\text {th }}$ dan $26^{\text {th }}-45^{\text {th }}$ menempati urutan ke dua dan dan ketiga dengan masing-masing berjumlah 56 sampel (54,9\%) dan 55 sampel $(45,8 \%)$. Kelompok umur $12^{\text {th }}$ $25^{\text {th }}$ menempati urutan nomor 4 dengan 2 sampel $(13,3 \%)$.

Tabulasi silang antara SM dengan golongan antipsikotik yang digunakan mendapatkan hasil yaitu SM ditemukan paling banyak pada kelompok pasien yang menggunakan TA sebesar 47 sampel atau sebesar $49,4 \%$ dari keseluruhan sampel yang menggunakan TA dan diikuti dengan kelompok yang menggunakan AA sebanyak 41 sampel $(49,3 \%)$. SM pada pasien yang menggunakan kombinasi terapi TA+AA didapatkan 31 sampel $(46,2 \%)$.

\section{Prevalensi Komponen Sindrom Metabolik}

Komponen SM pada penelitian ini meliputi Dislipidemia, Hipertensi, Obesitas, dan Gula Darah Puasa Terganggu. Dari keempat komponen SM ini, obesitas menempati urutan paling banyak pada pasien yang mengalami SM sebanyak 104 sampel (87,3\%). Komponen lain yang berada dibawah obesitas adalah dislipidemia sebanyak 91 sampel (76,4\%). Hipertensi dan Gula Darah Puasa Terganggu menempati urutan ke-3 dan ke- 4 dengan masing-masing 78 sampel $(65,5 \%)$ dan 72 sampel $(60,4 \%)$.

\section{PEMBAHASAN}

Penelitian sebelumnya yang dilakukan di luar Indonesia menunjukkan adanya angka SM yang cukup tinggi pada pasien dengan gangguan jiwa. Sayangnya data SM yang terjadi pada pasien gangguan jiwa di Indonesia sangat terbatas. Data SM pada pasien gangguan jiwa di Bali bahkan tidak ditemukan.

Hasil penelitian ini menunjukkan bahwa ditemukan prevalensi SM cukup tinggi sebesar $48,6 \%$ dari seluruh pasien yang dirawat dan jenis kelamin perempuan cenderung lebih banyak mengalami SM dibandingkan laki-laki. Hasil penelitian ini berbeda dengan penelitian yang dilakukan oleh Jung Sun Lee di Korea dimana 


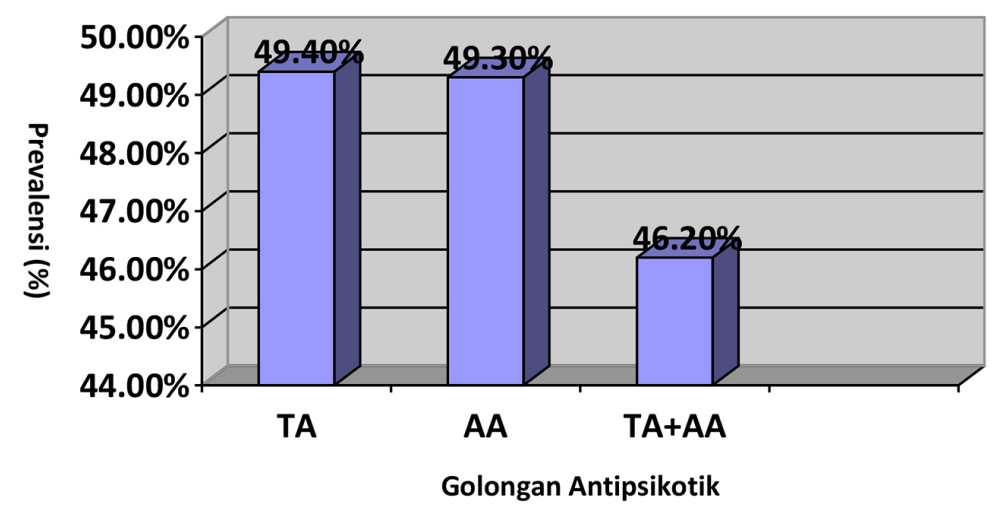

Grafik 3. Prevalensi Sindrom Metabolik Berdasarkan Penggunaan Golongan Antipsikotik. TA: Tipikal Antipsikotik, AA; Atipikal Antipsikotik

Tabel 2 Prevalensi Komponen Penyakit Sindrom Metabolik pada Sampel yang Memenuhi Kriteria SM

\begin{tabular}{ccc}
\hline KOMPONEN SM & JUMLAH (N=119) & PERSENTASE \\
\hline Dislipidemia & 91 & $76,4 \%$ \\
\hline GDP Tergangu & 72 & $60,4 \%$ \\
\hline Obesitas & 104 & $87,3 \%$ \\
\hline Hipertensi & 78 & $65,5 \%$ \\
\hline
\end{tabular}

didapatkan 36,5\% sampel mengalami SM dan didominasi oleh laki-laki sebanyak 40,8\% dan wanita sebanyak $32,2 \%$. Penelitian di Singapura oleh Jimmy Lee dkk juga mendapatkan hasil yang tidak jauh berbeda dimana angka SM yang didapat sebesar $46 \%$ dengan dominasi laki-laki sebesar $66 \%$ dan perempuan $34 \% .7,8$

Kelompok umur yang paling banyak mengalami SM adalah kelompok umur $>65$ th dan kelompok umur $45^{\text {th }}-65^{\text {th }}$ berada pada posisi kedua yang diikuti oleh kelompok umur 26th-45 th dan $12^{\text {th }}$ $25^{\text {th }}$. Data ini menunjukkan bahwa disregulasi metabolik sudah mulai terjadi pada usia remaja dan terus berkembang seiring pertambahan usia. Menurunnya metabolisme tubuh, disertai semakin berkurangnya aktifitas fisik menjadi penyebab utama terjadinya SM seiring dengan penambahan usia. $^{9}$

Beberapa studi menyebutkan peningkatan kasus SM pada usia yang lebih tua pada pasien dengan gangguan jiwa berkaitan dengan durasi penggunaan antipsikotik. Seringkali didapatkan penambahan usia berbanding lurus dengan lamanya durasi penggunaan antipsikotik. Mengingat adanya kemungkinan disregulasi metabolik terjadi pada usia yang lebih muda, sangat penting untuk dilakukan skrining dan penatalaksanaan lebih awal untuk mecegah terjadinya perburukan kondisi pada usia yang lebih tua khususnya pada pasien yang menggunakan antipsikotik jangka panjang. ${ }^{10}$

Antipsikotik menjadi pilihan utama dalam pendekatan farmakologis pada pasien dengan gangguan jiwa. Penelitian ini menunjukkan obat antipsikotik golongan TA menjadi pilihan utama dan paling banyak digunakan dibandingkan golongan AA maupun kombinasi dari kedua golongan ini $(\mathrm{AA}+\mathrm{TA})$. Sebagian besar terapi antipsikotik diberikan dalam jangka waktu yang lama.

Beberapa penelitian menunjukkan SM lebih banyak terjadi pada pasien yang menggunakan AA, tapi penelitian ini menunjukkan hasil yang berbeda dengan penelitian lain sebelumnya. Pada penelitian ini, SM terjadi paling banyak pada kelompok sampel yang menggunakan TA. Namun, hubungan antara penggunaan antipsikotik dengan SM belum diketahui secara pasti, ${ }^{10}$

Banyak faktor yang terlibat dalam hubungan antara penggunaan AA dengan SM seperti interaksi antara neuropeptida dopamin, histamin, orexigenik (anabolik), reseptor adrenergik dan muskarinik, serta kegagalan homeostasis glukosa. Beberapa penelitian juga menemukan adanya hubungan antara peningkatan berat badan dengan penggunaan obat AA walaupun tidak menutup kemungkinan beberapa jenis obat golongan TA seperti Klorpromazine juga dapat menyebabkan disregulasi metabolism. ${ }^{11}$

Hasil yang berbeda ini menunjukkan bahwa penggunaan antipsikotik golongan tertentu bukan satu-satunya faktor penyebab terjadinya SM pada pasien dengan gangguan jiwa. Selain penggunaan obat antipsikotik, terbatasnya aktivitas fisik selama perawatan juga mendukung terjadinya SM. Seringkali pasien menjadi sulit diarahkan untuk melakukan aktivitas fisik dikarenakan efek sedasi dari obat yang diminum. Hal ini membuat pasien cenderung terus ingin tidur. Gejala klinis yang muncul juga seringkali membuat pasien lebih banyak berdiam diri dan menarik diri dari lingkungan. Faktor gaya hidup yang cenderung pasif dan kerentanan terhadap stres adalah faktor yang turut berkontribusi terjadinya SM pada orang dengan gangguan jiwa., ${ }^{3,12}$

Asupan nutrisi yang berlebihan juga menjadi salah satu faktor terjadinya SM pada pasien gangguan jiwa. Nafsu makan yang meningkat sebagai bagian dari efek samping obat perlahan meningkatkan berat badan. Seringkali pasien tidak mengkonsumsi diet yang diberikan dari rumah sakit dan secara sembunyi-sembunyi mendapatkan 
makanan yang tidak sesuai dengan takaran diet yang diperlukan. Kebiasaan merokok yang sudah dibawa sejak sebelum masuk rumah sakit tidak serta merta dapat dihentikan oleh pasien. Kebiasaan buruk seperti ini berkontribusi pada terjadinya SM. Dibutuhkan peran keluarga dan tenaga kesehatan yang mampu memotivasi pasien untuk tetap melakukan aktivitas fisik, dan mengontrol asupan nutrisi yang sesuai dengan kebutuhan pasien. ${ }^{3}$

Komponen SM yang paling banyak ditemukan pada keseluruhan sampel yang mengalami SM adalah Obesitas. Obesitas didapatkan pada 104 sampel atau $87,3 \%$ dari seluruh sampel yang mengalami SM. Hasil yang sama juga didapatkan pada sebuah penelitian pada populasi umum yang dilakukan oleh M Pande Dwipayana dkk di Bali tahun 2003-2009. Penelitian ini mencatat obesitas menjadi gejala paling banyak ditemukan pada pasien dengan SM yaitu sebesar $35 \% .{ }^{13}$ Obesitas merupakan gejala paling awal dari SM walaupun ada pula ditemukan gejala SM tanpa disertai dengan obesitas. Prevalensi obesitas pada populasi skizofrenia saat ini diperkirakan berkisar $40 \%$ hingga $60 \%$ berbanding $30 \%$ pada populasi dewasa umum. Oleh karena itu obesitas dapat dijadikan sebagai parameter yang paling sederhana untuk mendeteksi SM. ${ }^{1,5}$

Obesitas seringkali dikaitkan dengan adanya stress pada pasien dengan gangguan jiwa, Pasien yang mengalami gangguan jiwa sering kali mengalami stres fisik maupun psikologis. Stres fisik dan psikologis ini menjadi salah satu faktor pencetus terjadinya obesitas. Stres yang berujung pada depresi menyebabkan terjadinya peningkatan sekresi Kortisol. Peningkatan Kortisol dalam tubuh menyebabkan meningkatnya insulin, leptin, dan Neuropeptida-Y yang berpengaruh pada sistem umpan balik di otak. Orang yang mengalami stres umumnya mengalami peningkatkan nafsu makan. Pada akhirnya, kombinasi peningkatan kortisol dan peningkatan asupan kalori berkontribusi pada penumpukan lemak visceral. ${ }^{3}$

Dislipidemia menjadi komponen SM yang jumlahnya terbanyak nomor dua dibawah obesitas dalam penelitian ini. Dislipidemia dikaitkan dengan efek samping dari penggunaan antipsikotik. Tidak semua antipsikotik memiliki efek samping tidak baik pada profil lipid. Kadar kolesterol yang lebih tinggi telah dilaporkan pada pasien yang diobati dengan klorpromazin dibandingkan yang menerima haloperidol. Bahkan clozapine yang merupakan agen antipsikotik atipikal dapat meningkatkan kadar trigliserida hampir dua kali lipat dari sebelumnya. Laporan-laporan terkait adanya dislipidemia sesudah penggunaan antipsikotik menjadi data penting untuk ditindaklanjuti, dan meningkatkan pengawasan pada pasien. ${ }^{3}$

Jumlah kasus diabetes mellitus dan Hipertensi menempati urutan ketiga dan keempat dalam penelitian ini. Skizofrenia telah dikaitkan dengan peningkatan risiko diabetes sejak abad kesembilan belas. Henry Maudsley adalah psikiater yang memperhatikan asosiasi antara diabetes dan skizofrenia. Hal ini dilakukannya jauh sebelum berkembangnya perawatan dengan antipsikotik. Sebuah penelitian menemukan prevalensi diabetes dan obesitas menjadi 2 sampai 4 kali lebih tinggi pada orang dengan skizofrenia daripada di populasi umum, dengan perkiraan prevalensi keseluruhan untuk diabetes di antara pasien dengan skizofrenia berkisar $16-25 \%{ }^{10}$

Pasien skizofrenia dengan diabetes seringkali memiliki prognosis yang buruk mengingat sulitnya mengarahkan pasien gangguan jiwa untuk tetap mengkonsumsi obat diabetes secara rutin dan mengontrol asupan nutrisi. Tingkat ketidakpatuhan terhadap pengobatan untuk diabetes pada ODGJ diperkirakan sekitar sebesar 50\%. Sebagian besar kasus baru diabetes tipe 2 yang disebabkan oleh obat antipsikotik terjadi dalam 6 bulan pertama pengobatan dan sering berhubungan dengan peningkatan berat badan yang signifikan atau obesitas. ${ }^{3,4}$

Beberapa penelitian menunjukkan bahwa adanya faktor genetika yang berperan pada terjadinya diabetes mellitus pada pasien gangguan jiwa khusunya skizofrenia. Hal ini dibuktikan dengan adanya peningkatan intoleransi glukosa pada seseorang yang memiliki saudara kandung dengan riwayat skizofrenia. Penelitian lain juga menunjukkan skizofrenia berkaitan dengan diabetes mellitus pada gen TCF7L2. Hal ini menunjukkan bahwa diabetes dan skizofrenia dapat diturunkan secara genetic. ${ }^{2,4}$

\section{KESIMPULAN}

Studi ini menemukan bahwa prevalensi SM pada pasien dengan gangguan jiwa yang dirawat di Rumah Sakit Jiwa Provinsi Bali sangat tinggi. Data penelitian ini menambah bukti bahwa pasien dengan gangguan jiwa memiliki risiko mengalami SM. Temuan ini juga menunjukkan bahwa pengelolaan pasien dengan gangguan jiwa tidak bisa hanya berfokus pada status mental, tapi diperlukan juga perhatian terhadap permasalahan fisik yang dialami oleh pasien. Sangat penting melibatkan berbagai disiplin ilmu dalam pengelolaan pasien gangguan jiwa untuk memberikan hasil yang optimal dan mencegah terjadinya perburukkan. 


\section{KONFLIK KEPENTINGAN}

Tidak ada konflik kepentingan terkait publikasi artikel ini.

\section{PENDANAAN}

Sumber pendaan penelitian adalah pendanaan pribadi dari peneliti.

\section{KONTRIBUSI AUTHOR}

Seluruh author berkontribusi dalam penyusunan naskah dengan author terakhir juga berkontribusi sebagai konsultan.

\section{DAFTAR PUSTAKA}

1. Wardhani YF, Paramita A. Pelayanan Kesehatan Mental Dalam Hubungannya Dengan Disabilitas Dan Gaya Hidup Masyarakat Indonesia (Analisis Lanjut Riskesdas 2007 Dan 2013). Buletin Penelitian Sistem Kesehatan 2016; Vol, 19 No, 1: 99-107

2. Papanastasiou E. Interventions for the metabolic syndrome in schizophrenia: a review. Ther Adv Endocrinol Metab 2012; 3(5) 141-62

3. Kucerovaa J, Babinska Z, Horska K, Kotolova $\mathrm{H}$. The common pathophysiology underlying the metabolic syndrome, schizophrenia and depression: A review. Biomed Pap Med 2015; 159(2):208-14

4. Yogaratnam J, Biswas N,Vadivel R, Jacob R. Metabolic Complications of Schizophrenia and Antipsychotic Medications: An Updated Review. East Asian Arch Psychiatry 2013;23:218

5. Seow LSE, Chong SA, Wang P, Shafie S, Ong $\mathrm{H}$, Subramaniam M. Metabolic syndrome and cardiovascular risk among institutionalized patients with schizophrenia receiving long term tertiary care. Comprehensive Psychiatry 2017;74:196-203

6. Shakeri J, Karimi K, Farnia V, Golshani S, Alikhani M. Prevalence of Metabolic Syndrome in Patients with Schizophrenia Referred to Farabi Hospital, Kermanshah, Iran. Oman Medical Journal 2016; Vol, 31:No, 4:270-75

7. Lee J, Nurjono M, Wong A, Salim A. Prevalence of Metabolic Syndrome Among Patients with Schizophrenia in Singapore. Ann Acad Med Singapore 2012;41:457-62

8. Lee JS, Kwon JS, Kim D, Kim SW, Kim JJ, et al. Prevalence of Metabolic Syndrome in Patients with Schizophrenia in Korea: A Multicenter Nationwide Cross-Sectional Study. Psychiatry Investig 2017;14(1):44-50

9. Said MA, Sulaiman AH, Habi M, Das S,et al. Metabolic syndrome and cardiovascular risk among patients with schizophrenia receiving antipsychotics in Malaysia, Singapore Med J 2012; 53(12): 801-07

10. Jeon SW. Unresolved Issues for Utilization of Atypical Antipsychotics in Schizophrenia: Antipsychotic Polypharmacy and Metabolic Syndrome. Int, J, Mol, Sci 2017; 18: 2174

11. Kyung Ko Y. The Prevalence of Metabolic Syndrome in Schizophrenic Patients Using Antipsychotics. Clinical Psychopharmacology and Neuroscience 2013;11(2):80-8

12. Vancampfort D, et al. Risk of metabolic syndrome and its components in people with schizophrenia and related psychotic disorders, bipolar disorder and major depressive disorder: a systematic review and meta-analysis. World Psychiatry 2015;14:339-47,

13. Dwipayana MP, Suastika K, Saraswati IMR, Gotera W, Budhiarta AAG, Sutanegara, et al. Prevalensi Sindroma Metabolik Pada Populasi Penduduk Bali, Indonesia. J Peny Dalam 2011; Volume 12 Nomor 1

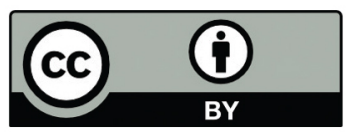

This work is licensed under a Creative Commons Attribution 